\title{
Electronic health record (EHR) projects in Canada: participation options for Canadian health librarians ${ }^{1}$
}

\author{
Sandra Barron ${ }^{2}$ and Sumanjit Manhas ${ }^{2}$
}

\begin{abstract}
Research question: What are the major issues in the implementation of electronic health record (EHR) systems in Canada and what competencies can Canadian health librarians bring to their participation in these projects? Data sources: Health informatics and library science databases were searched for EHR literature. Grey literature was located at Canada Health Infoway's website, on provincial and federal government websites, and by searching online news websites. Study selection: The data sources were searched for journal articles, reviews, newspaper articles, government publications, interviews, grey literature, dissertations, editorials, and discussions. Data extraction: Data were extracted from the data sources using search strategies and keywords outlined in Appendix A. Due to the scope and focus of this paper, search terms were selected to emphasize a Canadian context; in particular, a British Columbian perspective in regards to EHR implementation. Results: This paper draws on a body of evidence to discuss EHR implementation issues and health librarian involvement in Canada. There is a growing body of research in the American biomedical literature about health librarian participation in EHR implementation but little in the Canadian health literature. Conclusion: This is the first paper of its kind that proposes new roles for Canadian health librarians in EHR implementation. Health librarians' expertise in organizing and retrieving information makes them ideally suited for providing evidence-based medicine or consumer health information embedded directly in EHRs. Further research is needed to demonstrate the value of health librarians on EHR project teams.
\end{abstract}

\section{Research question(s)}

What are the major issues in the implementation of electronic health record (EHR) systems in Canada and what competencies can Canadian health librarians bring to their participation in these projects?

\section{Introduction}

This paper examines the status of electronic health record (EHR) systems (see Appendix B) in Canada and reviews the challenges of implementing those systems. Here, we also propose some new roles for Canadian health librarians who may want to venture into supporting EHR implementation within their organizations as part of informatics teams or strictly to link back to the library. According to the literature, it is unclear to hospital administrators, and clinical teams for that matter, what competencies health librarians bring to large EHR projects; health librarians may need to consider marketing their applicable skills or learning new ones to fully participate [1].

Historically, Canadian health librarians have provided information to patients but have rarely seen patient health records in their delivery of library services. The one exception to this fact may be when patients bring photocopies of their lab results to the health librarian. Patient information is generally seen to be the province of clinicians only. Health librarians, however, are beginning to (re)examine this issue due to the proliferation of both EHR systems and social media tools, such as Google Health and Microsoft Health Vault [2]. From the clinician's perspective, EHRs improve the flow of information and health librarians are a part of providing efficient access to authoritative information [3]. This information flow is also more likely to result in better patient care and decreased risks to patients due to better test tracking and drug prescribing [4]. At each point along the information path, links to health library services will make it possible for physicians to locate best practices that will result in cost efficiencies [5].

S. Barron ${ }^{3}$ and S. Manhas. School of Library, Archival \& Information Studies, University of British Columbia, BC, Canada.

${ }^{1}$ This paper has been peer-reviewed.

${ }^{2}$ Sandra Barron and Sumanjit Manhas received the Login Canada Student Paper Prize for this featured article.

${ }^{3}$ Corresponding author (e-mail: barron1@shaw.ca). 
Outside of the American health library literature, there is little research that describes emerging roles for health librarians in EHR projects in Canada. In the nonlibrary nursing literature, we identified a paper that discussed the involvement of a librarian on an EHR team [6]. At the Hunter-Bellevue School of Nursing in New York, the health librarian provided assistance to team members in a range of areas from teaching how to use controlled vocabularies to navigating complex computer interfaces [6]. In addition, members praised the librarian because of her expertise and knowledge; her presence as a technology expert also helped to reduce anxiety levels [6]. Clearly, health librarians can lend their considerable systems expertise to large informatics projects. Interestingly, Canada Health Infoway (see Appendix B) recommends that future EHR systems follow established international descriptive standards using the International Classification of Diseases (ICD) and the Systematized Nomenclature of Medicine (SNOMED) [7], further rationale for including librarians in EHR projects.

\section{Data sources}

Searches of the health informatics literature were performed in MEDLINE, EMBASE, and Cumulative Index to Nursing and Allied Health Literature (CINAHL) using the OvidSP and EBSCO interfaces. Library science literature was also searched using Library and Information Science Abstracts (LISA), Library Literature \& Information Science with Full Text and Library, Information Science \& Technology Abstracts (LISTA). Heuristic searches were conducted in Canadian Business and Current Affairs (CBCA), Google Scholar, Proquest Digital Dissertations, and Academic Search Premier. Grey literature was located at Canada Health Infoway's website, on provincial and federal government websites, and by searching online news websites. The retrieved results were limited to a publication date range of 2005-2011 to ensure currency of the literature.

\section{Study selection}

The data sources were searched for journal articles, reviews, newspaper articles, government publications, interviews, grey literature, dissertations, editorials, and discussions. A wide range of articles were reviewed to include as much of the literature available to provide a broad spectrum of view. The data sources provided information on EHR topics, such as EHR implementation issues in Canada, EHR initiatives in other countries, privacy and security issues, and health librarians' role in EHR projects.

\section{Data extraction}

Data were extracted from the data sources using search strategies and keywords outlined in Appendix A. Search terms were selected to emphasize a Canadian context, and specifically what is happening in British Columbia regarding EHR implementation, due to the scope and focus of the paper. The bibliographies of the papers examined led to other research that discussed EHR initiatives, but nothing further about Canadian health librarian involvement was noted. American literature was also included as a comparison to Canadian health librarian EHR projects.

\section{Results}

\section{Literature about EHR implementation in Canada}

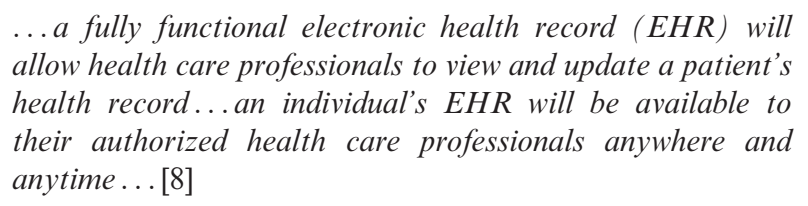

What did the health literature say about the implementation of Canadian EHR systems? The Health Council of Canada (HCC) is a critical player in this area; HCC released a report in 2010 asking for a much quicker implementation of EHR systems in Canada and criticized the delay especially in primary care. The report "Decisions, Decisions: Family Doctors as Gatekeepers to Prescription Drugs and Diagnostic Imaging in Canada" examines the critical roles that family physicians play in implementation of cost-effective solutions and in keeping health costs down [9]. However, the number of prescriptions filled in community pharmacies has nearly doubled since 2003, and requests for X-ray computed tomography (CT) scans and magnetic resonance imaging (MRI) have seen a $58 \%$ and $100 \%$ increase, respectively [10]. If EHR implementation is delayed, inappropriate use of medical services will continue to place a strain on dwindling health dollars [11].

A key challenge for EHR implementation in Canada is how to track patients as they move through the system. The HCC recommends the creation of national datasets for building pharmaco-economic and epidemiological information and assessing national health outcomes [11]. According to the HCC, EHRs are essential for encouraging physicians to follow clinical practice guidelines and in making best decisions for patients [10]. We feel it is reasonable to remind physicians of the critical role that health librarians play in leading clinicians to best medical evidence. In addition, we question whether the myriad of clinical decisions that are made every day by family physicians are based on the evidence. Here, where health library services are provided, Canadian health librarians are critical to leading busy practitioners to the best evidence and search services should always be made available to them.

In August 2010, the Canadian Medical Association (CMA) released a document to support the value of EHR projects across the country. It also reported that Canada spent $\$ 183$ billion on health care but ranked last among advanced countries in "value for money" [12]. The CMA document "Health care transformation in Canada: Change that works, care that lasts" [13] emphasizes the importance of EHRs in ensuring that we create a more sustainable system along five major areas:

1. improved health outcomes (patient safety; reduced waiting times) 
2. increased accessibility

3. better integration of health care categories

4. cost efficiencies

5. improved patient-provider satisfaction

Another worrying trend revealed by the literature is that Canada lags behind other countries in EHR implementation. According to a 2009 Commonwealth Fund study, $37 \%$ of Canadian physicians use some form of EHR system compared with $99 \%$ in the Netherlands, $97 \%$ in New Zealand, and 96\% in the United Kingdom [13]. The use of computers in Canadian physicians' offices is often confined to electronic billing and scheduling rather than patient care [10]. The slow implementation of Canadian EHR may partly explain why Canadian health librarians have not been involved in EHR systems to date. More expedient application of information tools in physicians' offices will shift the focus back to patients where librarians can become more involved. In the absence of academic health libraries that equally serve family physicians in Canada, a national virtual health library would certainly be advisable [14].

\section{Connecting health librarians to EHR projects}

In 2010, the Journal of the Medical Library Association (JMLA) - seeing the many potential roles of health librarians in EHR projects - devoted an entire journal issue to this topic [15-20]. Closer to home, the Canadian Health Libraries Association (CHLA) mentioned EHRs in 2002 as a strategic area in the early days of the National Network of Libraries for Health and, again in 2010, in developing the Canadian Virtual Health Library. However, the connection between EHRs and health librarians in Canada must be made more explicit because it represents a strategic area to connect them to the rise of evidence-based practice [14]. In addition, it would be prudent for health librarians to support and encourage the adoption of EHR technology and implementation due to a health librarian's role as an advocate for new technologies.

One direct way that health librarians can bring value to EHR projects is to ensure that evidence-based information is available (or linked from) within record systems [21]. Even if internal links to the library cannot be created, health librarians should continue to ensure that point-ofcare tools are easily accessible [21]. The integration of synthesized evidence into patient records presents new opportunities for health librarians looking to promote their expertise at points of care $[15,22]$. In fact, the health librarian's role in the clinical environment seems to be more established, according to one article:

\footnotetext{
...with the advent of clinical online resources, it offers further opportunities for librarians to provide the expertise needed to incorporate resources... the collaborative journey continues as librarians, now able to directly access EMRs, provide information about what resources to use and where best to place them... [16]
}

Health librarians are often perceived as the experts in medical informatics and locating "primary literature, meta-analysis, evidence from clinical trials and guidelines" for health professionals [17]. Historically, librarians have provided responsive services when in the clinic where patient questions are generated [18]. According to one American medical librarian, “... from LATCH (Literature Attached to the Chart)...to the clinical librarian and informationist concepts, [health] librarians have been at the forefront of efforts to provide knowledge to clinicians at the point of care..." [23]. In Canada, our information roles in the clinical setting can be further emphasized by reminding health providers of the importance of our collections and search skills.

A range of case studies in North America illustrates how various types of health librarians - academic, clinical, hospital and so on - have been able to integrate their libraries into the activities of building EHRs. At the 2009 Association of Academic Health Sciences Libraries Symposium, for example, connecting librarians to health information technologies was clearly shown [19]. The Vanderbilt University Medical Center is linking to the Eskind Biomedical Library from its EHR system and trains librarians to answer clinical questions [18]. Health librarians also help patients download consumer-level information using mobiles [17]. These are examples Canadian health librarians can use to promote their own involvement.

Health librarians can support EHR implementation simply by providing access to the best literature to support decision-making [24, 25]. Drug errors and errors in treatment and billing are a few areas that can be reduced [26]. By supplying researchers with access to best evidence, they will also be able to monitor emerging health threats based on the patients they are seeing; here, too, links to current print and electronic information are critical. Finally, health librarians can offer their expertise to EHR teams as they have done for years in hospital accreditation; these potential roles can be further examined within the context of their annual conferences and national association standards [27].

Electronic health records can be maintained at a fraction of the cost of manual systems and improve handling and processing times [28]. Other benefits include easy aggregation of information, quick retrieval of information in patient consultations, and the ability to discern health threats. Some health librarians point out that access to library resources and online help from the librarian should be made available at each step of searching EHR systems $[15,28]$.

At the Medical Library at Louisiana State University Health Centre, an AskALibrarian reference service was linked to EHRs to help physicians find evidence-based information [29]. The University of Pittsburgh Health Sciences Library embedded its own tool into EHRs and addressed clinicians' information needs at point of care. The development team designed a search box with subject tabs covering diagnosis, diseases, drugs, and evidencebased medicine (EBM). This approach improved clinical practice by delivering context-specific, evidence-based information [20]. Positioning the health library as a partner in the project "raise[d] the standard of care and improve[d] patient safety and satisfaction" [20]. This is supported in the literature where, 
Librarians certainly have a role to play in the development and implementation of EHRs because of their expertise in organizing, structuring, storing and retrieving information on demand. One of the areas being developed in EHRs is embedding links in individual patient records to online information resources that have a direct bearing on the particular patients [as in evidence-based medicine and consumer health]. Health sciences librarians are involved in finding ways to link primary research and the "best medical evidence" to specific patient records [30].

As noted, health librarians can also play a part in linking EHRs to consumer information files as the National Library of Medicine has done with MedlinePLUS and the Connect project [31]. The next stage of the overall process involves automatically generating questions using patient data and sending them to the library [20,22].

The scientific evidence connecting EHRs to improvements in patient safety is incomplete [32] and casts doubt on the return on investment [26]. A number of projects are plagued by cost overruns, computer crashes, and other hazards such as dehumanized care [26]. Further, some providers believe that EHRs increase the amount of time they spend on computers [33]. In any case, the savvy health librarian will keep a close watch for the emerging evidence that supports EHRs. In an age of increased surveillance by governments, the concerns about privacy should also be watched closely [34]. While serious, these concerns represent opportunities for Canadian health librarians who may want to educate clinicians about their rights.

\section{Health librarians and privacy protections}

Health librarians value patient confidentiality and privacy and support legislation that upholds those principles. In British Columbia (BC), the eHealth Personal Health Information Access and Protection of Privacy Act (eHealth Act) will permit health information to be shared online while maintaining strict controls on patient privacy (refer to Appendix B for more information on eHealth). The Act builds on protections in the Freedom of Information and Protection of Privacy Act (FOIPPA) and the Personal Information Protection Act (PIPA). Access to EHRs will be limited to doctors, nurses, and administrators who will obtain access depending on the information they need [24].

The British Columbia Civil Liberties Association (BCCLA) has raised its concerns that EHRs are a "massive privacy and security liability" [35] citing the following reasons: (1) the $\mathrm{BC}$ government is proceeding with implementation plans despite negative reports of both the Auditor General and Privacy Commissioner and (2) under the proposed legislation, governments will get unprecedented access to private health information [34, 35]. As one doctor said, "If privacy is not fully protected, we won't be building anything except the most valuable mother lode of information for data mining on Earth" [36].

Two recent Canadian examples of privacy breaches raise some serious concerns about EHRs. In Alberta, where "security [is] like Fort Knox" hackers looked at the personal data of 11000 patients residing on Alberta Health Services computers [34]. For the system to work, health workers must comply fully with confidentiality guidelines. In 2010, a Toronto study revealed that some health organizations discard sensitive information and expose citizens to identity theft. The study found that 7 out of 50 Ontario dumpsters contained personal health information on more than 100 patients, including their names, addresses, phone numbers, and medical conditions $[37,38]$. The professional values of health librarians ensure a commitment to improve the protection of patient information.

\section{Conclusion}

In Canada, there are a myriad of obstacles to overcome in the deployment of electronic health systems such as cost overruns, information security, and privacy [39]. But these areas can benefit from the perspectives of well-informed health librarians. Health librarians' expertise in organizing and retrieving information makes them ideally suited for providing evidence-based medicine or consumer health information embedded directly in EHRs. To 2020, EHRs offer many opportunities to move ahead on the principles of patient-centred care and the goal of creating a national virtual health library $[14,40]$. The extent to which EHRs will facilitate this evolution will depend on strong advocacy and the "reengineering [of] work processes" [41]. In the 21 st century, this re-engineering can potentially be transformative for health librarians. As Albert suggests, "...librarians can take a leading role in [EHRs]... by encouraging adoption and lending expertise in the selection, evaluation, application, and use of these systems, along with identification of user needs and optimal structuring of answers to clinical queries at the point of care." [23].

Several expert opinion reports and qualitative studies of successful EHR implementation were located for this paper. However, the authors were surprised to learn of very little research about health librarian roles in EHR projects and nothing specifically about Canadian health librarians. That said, all health librarians are positioned to participate in projects that take advantage of their knowledge of organizational systems and computers and EHR systems are no exception [18]. Participation may simply be a matter of volunteering at the most opportune time within the hospital or health organization in which the health librarian works. More research into the skills, knowledge, and abilities that health librarians need to participate in EHR implementation is clearly needed.

Looking to the future, we recommend that the Canadian Health Libraries Association consider programming relevant workshops for health librarians who may want to increase their knowledge of EHR systems and the other issues discussed in this paper. This approach could be a starting point towards building evidence to support our involvement in EHR implementation. Due to the lack of Canadian literature on EHR implementation to date, particularly the lack of literature on the involvement of Canadian health librarians in EHR implementation, the Canadian Health Libraries Association should support the EHR initiative. 


\section{Acknowledgements}

The authors would like to thank Dean Giustini, Reference Librarian at the University of British Columbia Biomedical Branch Library, for his advice and support throughout the creation of this paper.

\section{References}

1. Saimbert MK, Zhang Y, Pierce J, Moncrief ES, O'Hagan KB, Cole P. Medical librarians supporting information systems project lifecycles toward improved patient safety. $J$ Healthc Inf Manag. . 2010;24(1):52-6.

2. Kidd MR. Personal electronic health records: MySpace or HealthSpace? BMJ 2008;336:1029-30. doi:10.1136/bmj.39567. 550301.80 .

3. Office of the Auditor General of Canada [Internet]. Ottawa: Auditor General; c2010 [updated 2010 Apr; cited 2011 Jan 22]. Electronic Health Records in Canada-An Overview of Federal and Provincial Audit Reports [about 22 screens]. Available from: http://www.gov.pe.ca/photos/original/ag_ ehealth.pdf.

4. Canada Health Infoway [Internet]. Toronto: Infoway; c2010 [cited 2010 Nov 17]. EHR Advancements in Canada [about 3 screens]. Available from: http://www.infoway-inforoute.ca/ lang-en/about-ehr/advancements.

-5. Hillestad R, Bigelow J, Bower A, et al. Can electronic medical record systems transform health care? potential health benefits, savings, and costs. Health Aff. 2005;24(5):1103-17. doi:10.1377/hlthaff.24.5.1103.

6. Griffin-Sobel J, Acee A, Sharoff L, Cobus-Kuo L, Woodstock-Wallace A, Dornbaum M. A transdisciplinary approach to faculty development in nursing education technology. Nurs Educ Perspect. 2010;31(1):41-3.

7. Canada Health Infoway [Internet]. Toronto: Infoway; c2010 [cited 2010 Nov 17]. The Electronic Health Record Solution Blueprint: A Roadmap for Planning and Implementation in Canada [about 4 screens]. Available from: https://www. infoway-inforoute.ca/working-with-ehr/knowledgeway/know ledge-center/657.

8. Office of the Auditor General of Canada [Internet]. Ottawa: Auditor General; c2011 [updated 2010 Apr 20; cited 2011 Jan 22]. Electronic Health Records in Canada-An Overview of Federal and Provincial Audit Reports [about 12 screens]. Available from: http://www.oag-bvg.gc.ca/internet/English/ parl_oag_201004_07_e_33720.html.

9. Weeks C. Get electronic health records - stat, watchdog urges. The Globe and Mail. 2010 Sept 27;Sect. A:1-2.

10. Health Council of Canada [Internet]. Toronto: Health Council; c2010 [cited 2010 Nov 20]. News Release: New Report Shows Overuse of Diagnostic Imaging and Inappropriate Prescribing. Health Council of Canada Releases Report on How Physicians' Decisions Affect Health Care Services in Canada [about 4 screens]. Available from: http://tiny.cc/tbnwl.

11. Health Council of Canada [Internet]. Toronto: Health Council; c2010 [cited 2010 Nov 20]. Decisions, Decisions: Family Doctors as Gatekeepers to Prescription Drugs and Diagnostic Imaging in Canada [about 50 screens]. Available from: http://tiny.cc/f3fy1.
12. Fitzpatrick M [Internet]. Toronto: PostMedia News; c2010 [updated 2010 Aug 25; cited 2010 Nov 20]. New Medical Association Boss Says Canadians Deserve Better [about 5 screens]. Available from: http://tiny.cc/cue37bjcjk.

13. Canadian Medical Association [Internet]. Ottawa: Canadian Medical Association; c2010 [cited 2010 Nov 20]. Health Care Transformation in Canada: change that Works, Care that Lasts [about 48 screens]. Available from: http://tiny.cc/ ihv90.

14. National Network of Libraries for Health [Internet]. Toronto: NNLH; c2010 [updated 2010 Aug 31; cited 2011 Jan 22]. Activities [about 6 screens]. Available from: http://www.chlaabsc.ca/nnlh/activities.html.

15. Jones DA, Shipman JP, Plaut DA, Selden CR. Characteristics of personal health records: findings of the Medical Library Association/National Library of Medicine joint electronic personal health record task force. $J$ Med Libr Assoc. 2010;98(3):243-9. doi:10.3163/1536-5050.98.3.013.

16. Welton NJ. The University of Washington electronic medical record experience. J Med Libr Assoc. 2010;98(3):217-9. doi:10.3163/1536-5050.98.3.008.

17. Curtis JA. Electronic health records, platforms, libraries, and evidence: report on the Association of Academic Health Sciences Libraries symposium's keynote presentation by Kenneth Mandl. J Med Libr Assoc. 2010;98(3):206-9. doi:10.3163/1536-5050.98.3.005.

18. Giuse NB, Williams AM, Giuse DA. Integrating best evidence into patient care: a process facilitated by a seamless integration with informatics tools. $J$ Med Libr Assoc. 2010;98(3):220-2. doi:10.3163/1536-5050.98.3.009.

19. Curtis JA. Introduction: The Association of Academic Health Sciences Libraries symposium: electronic health records and knowledge-based information: state-of-the-art and roles for libraries in health information technology. $J$ Med Libr Assoc. 2010;98(3):204-5. doi:10.3163/15365050.98.3.004.

-20. Epstein BA, Tannery NH, Wessel CB, Yarger F, LaDue J, Fiorillo AB. Development of a clinical information tool for the electronic medical record: a case study. J Med Libr Assoc. 2010;98(3):223-7. doi:10.3163/1536-5050.98.3.010.

21. Wood MS. Introduction to health sciences librarianship. New York: Haworth Press, Taylor and Francis Group; 2008. p. $279-80$.

22. Haynes C. Linking to knowledge-based systems from the electronic health record: the librarian's role. J Hosp Librarian. 2007;7(4):121-9. doi:10.1300/J186v07n04_09.

23. Albert KM. Integrating knowledge-based resources into the electronic health record: history, current status, and role of librarians. Med Ref Serv Q. 2007;26(3):1-19. doi:10.1300/ J115v26n03_01.

24. Ministry of Health Services [Internet]. Victoria: Government of British Columbia; c2010 [cited 2010 Nov 22]. eHealth [about 3 screens]. Available from: http://tiny.cc/5zgh6.

25. DesRoches CM, Campbell EG, Rao SR, et al. Electronic health records in ambulatory care - a national survey of physicians. $N$ Engl J Med. 2008;359:50-60. doi:10.1056/ NEJMsa0802005. 
26. Greenhalgh T, Potts HW, Wong G, Bark P, Swinglehurst D. Tensions and paradoxes in electronic patient record research: a systematic literature review using the meta-narrative method. Milbank Q. 2009;87(4):729-88. doi:10.1111/j.14680009.2009.00578.x.

27. Canadian Health Library Association [Internet]. Toronto: CHLA/ABSC; c2010 [updated 2010 Mar 23; cited 2011 Jan 20]. CHLA/ABSC Representative to Accreditation Canada [about 3 screens]. Available from: http://www.chla-absc.ca/ node $/ 258$.

28. Perera G, Holbrook A, Thabane L, Foster G, Willison DJ. Views on health information sharing and privacy from primary care practices using electronic medical records. Int $J$ Med Inform. 2011;80(2):94-101. Epub 2010 Dec 16. doi:10.1016/j.ijmedinf.2010.11.005.

29. Jones DA, Esparza J, Duggar DC. Reflecting on the concept of connecting clinicians with library resources and librarians through the electronic health record system. MLA Abstracts. MLA 2010: MLA'10 Reflect and Connect; 2010 May 21-6; Washington, DC. Available from: http://www.mlanet.org/am/ am2010/pdf/mla10_abstracts.pdf.

30. Cleveland AD, Cleveland DB. Health informatics for medical librarians. New York: Neal-Schuman Publishers; 2009. pp. $153-68$.

31. US National Library of Medicine [Internet]. Bethesda: NLM; c2010 [updated 2010 Nov 9; cited 2011 Jan 24]. MedlinePlus Connect: Linking Electronic Health Records (EHRs) to MedlinePlus Health Information [about 2 screens]. Available from: http://www.nlm.nih.gov/medlineplus/connect/overview. html.

32. Brown M, Shaw N, Grimm N, Muttitt S, Gebran J. Electronic health records and patient safety: what lessons can Canada learn from the experience of others? Healthc $Q$. 2008;11(1):112-9.

33. Kluger J [Internet]. Florida: Times; c2011 [updated 2009 Mar 25; cited 2010 Nov 26]. Electronic Health Records: What's Taking So Long [about 4 screens]. Available from: http://tiny. $\mathrm{cc} / 1 \mathrm{rcin}$.

34. Vonn M. The real impact of the e-health act. Advocate. 2009;67(6):753-8.

35. British Columbia Civil Liberties Association [Internet]. Vancouver: BCCLA; c2010 [updated 2010 Mar 15; cited 2010 Nov 29]. Submission from the British Columbia Civil
Liberties Association to the Special Committee to Review the Freedom of Information and Protection of Privacy Act [about 12 screens]. Available from: http://tiny.cc/1725r.

36. Foreman J [Internet]. Los Angeles: LA Times; c2011 [updated 2006 Jun 26; cited 2010 Nov 10]. At Risk of Exposure [about 2 screens]. Available from: http://tiny.cc/znsmg.

37. Godfrey T [Internet]. Toronto: Toronto Sun; c2011 [updated 2010 Oct 28; cited 2010 Nov 10]. Doctors' Office Need to Shred Patient Details: Watchdog [about 2 screens]. Available from: http://tiny.cc/w9mqj.

38. Nguyen L [Internet]. Toronto: PostMedia News; c2010 [updated 2010 Oct 28; cited 2010 Nov 10]. Dumpster Diving Turns Up Personal Information in Toronto Area [about 3 screens].

39. Ludwick DA, Doucette J. Adopting electronic medical records in primary care: lessons learned from health information systems implementation experience in seven countries. Int $J$ Med Inform. 2009;78:22-31. doi:10.1016/j.ijmedinf. 2008.06.005.

40. Goldstein D, Groen PJ, Ponkshe S, Wine M. Medical informatics 20/20: quality and electronic health records through collaboration, open solutions, and innovation. Sudbury, MA: Jones and Bartlett Publishers; 2007. pp. 457-96.

41. Tan J. E-health care information systems: an introduction for students and professionals. San Francisco: Jossey-Bass; 2005. p. 115.

42. Giustini D [Internet]. Vancouver: HLWIKI Canada; c2011 [updated 2011 Jan 2; cited 2011 Jan 20]. Electronic Patient Record [about 3 screens]. Available from: http://tiny.cc/h9ogb.

43. U.S. Department of Health \& Human Services [Internet]. Washington, DC: The Office of the National Coordinator for Health Information Technology; c2011 [cited 2011 Apr 29]. Health IT Buzz: EMR vs EHR - What is the Difference? [about 6 screens]. Available from: http://www.healthit.gov/ buzz-blog/electronic-health-and-medical-records/emr-vs-ehrdifference/.

44. Canada Health Infoway [Internet]. Toronto: Infoway; c2010 [cited 2010 Nov 17]. Canada Health Infoway [about 1 screen]. Available from: http://www.infoway-inforoute.ca/lang-en/.

45. Health Canada [Internet]. Ottawa: Government of Canada; c2010 [updated 2010 Aug 09; cited 2011 Jul 17]. eHealth [about 2 screens]. Available from: http://www.hc-sc.gc.ca/hcssss/ehealth-esante/index-eng.php. 


\section{Appendix A: Keywords used for searching MEDLINE, EMBASE, CINAHL, Digital Dissertations, Academic Search Premier, Compendex, Web of Science, Scirus, and Google Scholar}

1. computer communication network* OR computerized patient record* OR e-health OR ehealth OR electronic chart* OR e-chart* OR echart* OR electronic health record* OR electronic patient record* OR electronic medical record* OR EPRs OR EHRs OR EMRs OR medical records systems, computerized OR health informatic* OR hospital information system* OR medical informatic*

2. health librarian* OR health informatician* OR health information specialist*

3. Canada OR United States OR British Columbia OR Canada Health Infoway OR Infoway

4. 1 AND 2 AND 3

5. Various combinations

\section{Appendix B: Definitions}

Electronic Health Records (EHRs) are secure, private lifetime records that describe a person's health history [42]. They comprise information from several sources in hospitals, clinics, family practices, pharmacies, and laboratories. Some information captured by EHRs includes [42]

- patient demographics; medical histories

- medication and allergy list; laboratory test results

- diagnostic images (X-rays, MRIs, CT scans)

- billing records

- appointment reminders

- living wills; powers of attorney

EHR is a term often confused with the electronic patient record (EPR) and electronic incidental record. The term electronic medical record (EMR) is also used [42].

Electronic Medical Records (EMRs) are an electronic version of a patient's paper charts in a clinician's office which include the patient's medical and treatment history in one clinical practice [43]. Some information captured by EMRs includes [43]

- tracking data over time

- identifying preventive screenings or checkups for patients

- monitoring and improving quality of care

Canada Health Infoway (Infoway) was created in 2001 as an independent, non-for-profit corporation in Canada. It is funded by the federal government to oversee development of a Pan-Canadian EHR system. Infoway has received \$2.14 billion dollars to develop national requirements for EHRs. It funds up to $75 \%$ of jurisdictional costs of EHR implementation and uses a gated funding model [44].

eHealth (also written e-health) dates back to the 1990s and refers to the delivery of health care supported by the application of information and communication technologies (ICTs) [45]. Related areas include medical informatics, telemedicine, health management, information systems, mobile health, and social media. Use of the various terms varies considerably. 
This article has been cited by:

1. Halbert Helen. 2013. The State of Clinical Librarianship in Canada: a Review of the Literature, 1970-20131. Journal of the Canadian Health Libraries Association 34:02, 69-74. [Abstract] [Full Text] [PDF] [PDF Plus] 